\title{
AKTIVITAS ANTIINFLAMASI EKSTRAK DAUN KEREHAU (Callicarpa longifolia L.)
}

\author{
Ferry Semiawan*, Islamudin Ahmad, Muhammad Amir Masruhim \\ Laboratorium Penelitian dan Pengembangan FARMAKA TROPIS, Fakultas Farmasi, \\ Universitas Mulawarman, Samarinda, Kalimantan Timur \\ *email: ferrysemiawan@ rocketmail.com
}

\begin{abstract}
ABSTRAK
Penelitian mengetahui Akitivitas Antiinflamasi dari ekstrak daun Kerehau (Callicarpa longifolia Lamk). Metode yang digunakan pada pengujian antiinflamasi adalah metode Pletismometer. Ekstrak metanol daun kerehau memiliki aktivitas sebagai antiinflamasi terhadap peradangan atau inflamasi. Konsentrasi yang diujikan yaitu dosis $250 \mathrm{mg}, 300 \mathrm{mg}$, $350 \mathrm{mg}$ dengan kontrol positif Deksametasone dan negatif aqua destillata. Berdasarkan pengukuran penurunan radang inflamasi terdapat perbedaan bermakna antara perlakuan dan kontrol, dari hasil pengukuran menunjukan bahwa konsentrasi dosis $250 \mathrm{mg}$ adalah konsentrasi yang paling efektif, Dilakukan juga uji metabolit sekunder daun kerehau diperoleh hasil uji positif mengandung metabolit sekunder tannin, saponin flavanoid dan alkaloid.
\end{abstract}

\section{Kata kunci: Daun Kerehau (Callicarpa longifolia Lamk), Inflamasi}

\section{PENDAHULUAN}

Berdasarkan pengalaman empiris masyarakat, Daun kerehau digunakan sebagai obat bengkak dengan cara ditumbuk dan ditempelkan pada bengkak kemudian dibalut dan ditutup kain penutup agar tumbukan daun dapat menempel pada bengkak. Tumbuhan ini memiliki khasiat secara empiris digunakan sebagai obat masuk angin dan digunakan juga sebagai pupur atau bedak. Dipublikasikan oleh Fransiska (2010) yang melakukan penelitian secara eksloratif pada beberapa tumbuhan yang berkhasiat obat salah satunya yakni tumbuhan kerehau sehingga diduga tumbuhan ini memiliki metabolit sekunder yang memiliki aktivitas mengobati atau mengurangi inflamasi.

Berdasarkan Penggunaannya bahan alam memiliki kelebihan yaitu efek terapeutiknya bersifat konstruktif, efek samping yang ditimbulkan juga sangat kecil sehingga bahan alami relatif lebih aman dari pada bahan kimiawi atau sintetik yang beredar dipasaran. Inflamasi merupakan suatu respons protektif normal terhadap luka jaringan yang disebabkan oleh trauma fisik, zat kimia yang merusak atau zat-zat mikrobiologik. Inflamasi juga merupakan usaha tubuh untuk menginaktivasi atau merusak organisme yang menyerang, menghilangan zat iritan dan mengatur derajat perbaikan jaringan. Jika terjadi proses penyembuhan biasanya peradangan akan mereda (Mycek,2010).

Tujuan inflamasi yaitu untuk memperbaiki jaringan yang rusak serta mempertahankan diri terhadap infeksi. Tanda-tanda inflamasi adalah berupa kemeraham (rubor), panas (kalor), nyeri (dolor), pembengkakan (tumor). Inflamasi akut adalah inflamasi yang terjadi segera setelah adanya rangsang iritan. Pada tahap 
ini terjadi pelepasan plasma dan komponen seluler darah ke dalam ruangruang jaringan ekstraseluler. Termasuk didalamnya granulosit neutrofil yang melakukan pelahapan (fagositosis) untuk membersihkan debris jaringan dan mikroba (Soesatyo, 2002).

Pengobatan inflamasi mempunyai dua tujuan utama. Pertama meringankan rasa nyeri yang sering merupakan gejala awal yang terlihat; dan kedua, memperlambat atau membatasi proses perusakan jaringan. Obat-obat antiinflamasi nonsteroid (AINS) dan kortikosteroid sama-sama memiliki kemampuan untuk menekan tanda-tanda dan gejala-gejala inflamasi, namun sayangnya kedua golongan obat ini yang biasa digunakan dalam pengobatan inflamasi seringkali menimbulkan efek yang merugikan dan berbahaya seperti kerusakan gastrointestinal, nefrotoksik dan hepatotoksik (Katzung, 2002)

\section{METODE PENELITIAN}

\section{Bahan}

Daun Kerehau (Callicarpa longifolia Lamk) yang akan diteliti daun dewasa berwarna hijau dan masih keras; Pelarut metanol, Tikus sebagai hewan uji, Karagenan, Na-CMC sebagai bahan pengsuspensi, $\mathrm{NaCl}$ (Natrium Clorida) fisiologis $0,9 \%, \quad$ aquades, dan Deksametason.

\begin{abstract}
Alat
Timbangan analitik ADAM PGW 253i; spoid oral; spoid injeksi; sentrifuge; peralatan gelas; batang pengaduk; timbangan analitik; penangas air; labu takar, dan Inkubator.
\end{abstract}

\section{Prosedur Penelitian}

Ekstrak daun Kerehau (Callicarpa longifolia Lamk) diperoleh dengan cara maserasi. Pemisahan ekstrak dengan pelarut dengan menggunakan alat Rotavapor dimana pemisahan terjadi berdasarkan titik didih. Dibuat 3 konsentrasi dosis ekstrak yakni 250 $\mathrm{mg} / \mathrm{kgBB}, 300 \mathrm{mg} / \mathrm{kgBB}$, dan $350 \mathrm{mg} / \mathrm{kg}$ BB. Proses pengujian menggunakan 15 ekor tikus putih dan dibagi menjadi lima kelompok yang terdiri dari 3 ekor tikus putih. Kelompok pertama sebagai kontrol positif yang diberikan oral obat pembanding deksametason. Kelompok kedua sebagai kontrol negatif tanpa diberi ekstrak ataupun obat pembanding dan masing-masing tiap kelompok hewan uji dibuat radang pada tiap telapak kaki hewan uji secara intraplantar . Kelompok ketiga hingga kelima sebagai perlakuan pengujian yang diberi ekstrak daun kerehau secara oral setiap selang waktu 120 menit. Pengujian dilakukan selama 12 hari. Setiap selang waktu 60 menit selama 6 jam diukur telapak kaki hewan uji tiap kelompok menggunakan pletismometer.

\section{HASIL DAN PEMBAHASAN}

Pengujian aktivitas antiinflamasi ekstrak daun kerehau merupakan suatu pengujian untuk mengetahui kemampuan ekstrak dalam menurunkan inflamasi dengan cara melihat penurunan diameter radang terhadap tingkat pengenceran ekstrak yang kemudian diukur yang bertujuan ekstrak daun kerehau mampu menurunkan inflamasi pada tikus putih dan dapat memberikan pengaruh yang berbeda terhadap aktivitas antiinflamasi dan variasi dosis ekstrak daun kerehau. Dari hasil penelitian dapat disimpulkan bahwa variasi dosis ekstrak metanol daun kerehau 
dapat menurunkan peradangan pada tikus putih.

Penelitian ini dimulai dengan melakukan uji pendahuluan yang dilakukan menggunakan tikus putih untuk menentukan dosis yang akan diujikan. Hasil uji pendahuluan diperoleh berberapa variasi dosis yang akan digunakan dalam penelitian. Pada saat pelaksanaan penelitian dilakukan dengan cara menyuntikan suspensi karagenin pada telapak kaki hewan uji tikus putih secara intraplantar kemudian diberikan dosis ekstrak daun kerehau secara oral tiap selang waktu 120 menit selama 6 jam. Pengujian aktivitas antiinflamasi ekstrak metanol daun kerehau digunakan 3 variasi konsentrasi tersebut. Diperoleh data hasil aktivitas antiinflamasi daun kerehau yang menggunakan metode pletismometer dan pengukuran rata-rata diameter penurunan radang atau antiinflamasi ekstrak metanol daun kerehau terhadap inflamasi pada kaki tikus. Grafik aktivitas antiinflamasi ekstrak metanol daun kerehau dapat dilihat pada Gambar 1.

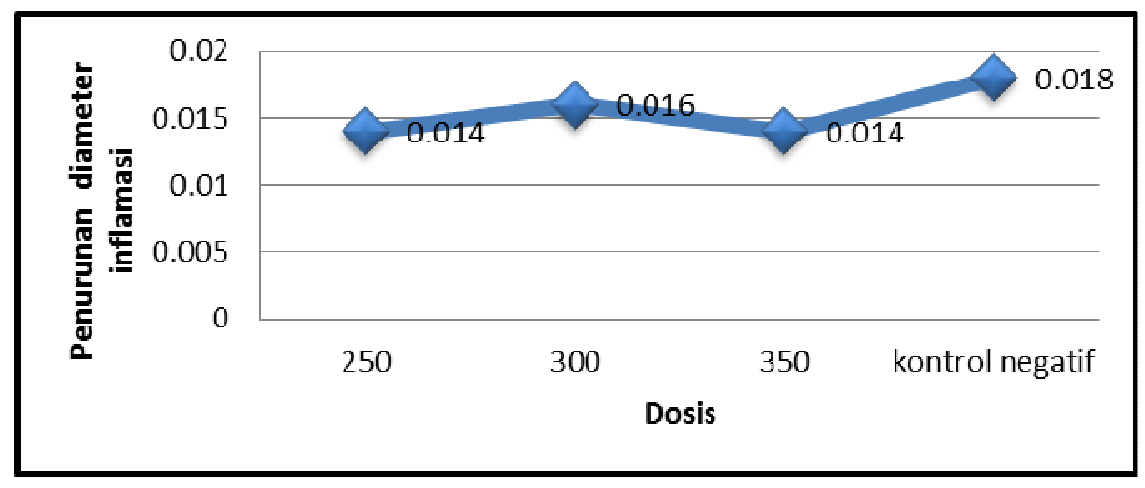

Gambar 1. Aktivitas Antiinflamasi Ekstrak Metanol Daun Kerehau

Ekstrak metanol daun kerehau mampu memberikan aktivitas antiinflamasi yang ditunjukkan dengan terjadinya penurunan diameter inflamasi pada telapak kaki tikus, ini terlihat pada gambar 1 . Penurunan diameter inflamasi pada ekstrak metanol daun kerehau ditunjukkan pada konsentrasi dosis 250 merupakan konsentrasi efektif dimana konsentrasi dosis 350 tidak jauh berbeda dengan 250 dari hasil tersebut diambil dosis dari ekstrak metanol daun kerehau yaitu konsentrasi terkecil yang paling baik memberikan aktivitas antiinflamasi karena dapat menurunkan diameter radang dengan baik. Pada konsentrasi dosis 300 mg aktivitas antiinflamasi mengalami penurunan tetapi tidak jauh berbeda dengan kontrol negatif yang tidak diberi perlakuan. Sedangkan untuk kontrol negatif tidak memberikan aktivitas antiinflamasii, hal ini terlihat dari tidak terjadinya penurunan diameter radang. Tujuan dari penggunan kontrol negatif itu sendiri adalah untuk memastikan inflamasi yang terbentuk bukan merupakan pengaruh dari pelarut air yang digunakan untuk melarutkan ekstrak, tetapi murni dari senyawa aktif yang terkandung di dalam ekstrak metanol daun kerehau.

\section{KESIMPULAN}

Ekstrak metanol daun kerehau memiliki aktivitas sebagai antiinflamasi terhadap peradangan atau inflamasi. 


\section{DAFTAR PUSTAKA}

1. Fransisca, M.S.2010. Etnofarmakologi dan Pemakaian Tanaman Obat Suku Dayak Tunjung di Kalimantan Timur. Jakarta; Media Litbang Kesehatan.

2. Katzung, B.G. 2002. Farmakologi Dasar dan Klinik. Jakarta; Penerbit Salemba

3. Mycek, M.J.; Harvey,R.A.; \& Champe, P.A. 2001. Farmakologi Ulasan Bergambar edisi kedua. Jakarta; Penerbit Widya Medika
4. Soesatyo, M.H.N.E. 2002. Proses Inflamasi, Penggunaan Analgetik dan Antiinflamasi Non Steroid Secara Rasional, Bagian Farmakologi dan Toksikologi, Fakultas Kedokteran Universitas Gadjah Mada, Yogyakarta,27-38

5. Fitriyani, A.; Winarti, L.; Siti, M.; \& Nuri. 2011. Uji Antiinflamasi Ekstrak Daun Sirih Merah (Piper crocatum Ruiz \& Pay) Pada Tikus Putih. Jakarta; Majalah Obat Tradisional. 